The Dock-in Model of Music Culture and Cross-cultural Perception Author(s): Thomas Fritz

Source: Music Perception: An Interdisciplinary Journal, Vol. 30, No. 5 (June 2013), pp. 511-516 Published by: University of California Press

Stable URL: http://www.jstor.org/stable/10.1525/mp.2013.30.5.511

Accessed: 21/01/2015 09:44

Your use of the JSTOR archive indicates your acceptance of the Terms \& Conditions of Use, available at http://www.jstor.org/page/info/about/policies/terms.jsp

JSTOR is a not-for-profit service that helps scholars, researchers, and students discover, use, and build upon a wide range of content in a trusted digital archive. We use information technology and tools to increase productivity and facilitate new forms of scholarship. For more information about JSTOR, please contact support@ jstor.org. 


\section{The Dock-in Model of Music Culture and Cross-cultural Perception}

Thomas Fritz

Max Planck Institute for Human Cognitive and Brain Sciences, Leipzig, Germany; Institute for Psychoacoustics and Electronic Music, Gent, Belgium; University of Leipzig, Leipzig, Germany

This PAPER PROPOSES A MODEl THAT AIMS TO illustrate how different human music cultures intersect and "dock in" to a set of music features that are universally perceived, while also displaying culture-specific features that must be learned. The model emphasizes that over historic time the music in a given culture can "dock into" and "dock out of" cues that are universally perceived, shifting its potential for cross-cultural perception and interaction. While this model accounts for music ethnological evidence reviewed here, it also explains why universals of music perception cannot simply be determined by specifying the common denominator between the formal music features of all cultures. This report suggests that the Dock-in Model can be generalized to account for cross-cultural perception more generally.

Received: January 4, 2012, accepted December 14, 2012.

Key words: universal, Mafa, emotional expression, cross-cultural, communication

$\mathrm{T}$ HE INVESTIGATION OF MUSIC UNIVERSALS IS important to the understanding of (A) the biological roots of music, and (B) how music may have served human evolution and civilization.

FORMAL VS. FUNCTIONAL PROPERTIES OF MUSIC

Music universals can be examined at two levels: 1) the response to formal music features such as pitch, consonance/dissonance, emotional expression, etc., and 2) in terms of its functional properties, referring to its functional role for individuals and societies. Such functional purposes of music are often surprisingly similar between cultures (Nettl, 2005, p. 244), and some of them are probably universal (such as the mediation of ritual communitas experience by music (Turino, 2008; Turner, 1969) and regulate humanity's relationship to the supernatural
(Nettl, 2005). The model presented here elucidates the role of universal and culture-specific features in responses to music, thus taking account of the perception of formal music features rather than its functional roles.

\section{VARIETY OF MUSIC}

In order to investigate music universals, it is helpful to have a concept of what music may be. This is challenging because the design features of music are variable and various (Fitch, 2005). Furthermore, although the functional purposes of music are often surprisingly similar between cultures and may be generically identifiable, the contexts where music is involved differ to a great extent between cultures (Cook, 1998). Consequently, it is not a simple matter to agree on what music is. For example, many ethnic groups do not even have a term for music at all (Fritz et al., 2009) because it is an integral part of various rituals. If one tried to name a formal common denominator of what might be considered music in all cultures of the earth, there might be nothing at all besides the possibility that it relates to some form of intentionally organized sound. However, this does not imply that there are no universals of music perception.

\section{CHALLENGES INVESTIGATING MUSIC UNIVERSALS}

An unbiased investigation of music universals is very challenging. Music styles from different cultures (musical forms) influence each other, directly or indirectly. Because music is well fit for media broadcast (it is entertaining to listeners), globalization augments the reciprocal influence of musical forms. An investigation of music universals with a specific music would ideally require participants who are completely naïve to this music. Given the extent of Western music propagation, this is difficult with Western music stimuli. Furthermore, an entirety of music universals cannot be accounted for by investigating a response to Western music in a Western type of experimental setting involving only listening (because then the methods of exploration are not independent of the concepts and practices of Western music). The investigation of music universals is complicated by the fact that even individuals who have only rarely listened to music from a different music culture, and perhaps without paying explicit attention to it

Music Perception, volume 30, issue 5, pp. 511-516, issn 0730-7829, electronic issn 1533-8312. C 2013 by the Regents of the university of California all RIGHTS RESERVED. PLEASE DiRECT ALL REQUESTS FOR PERMISSION TO PHOTOCOPY OR REPRODUCE ARTICLE CONTENT THROUGH THE UNIVERSITY OF CALIFORNIA PRESS'S RightS AND PERMiSSIONS WEBSITE, HTtP://WWW.UCPRESSJOURNALS.COM/REPRINTINFO.ASP. DOI: 10.1525/MP.2013.30.5.511 
(e.g., while listening to the radio or watching a movie) acquire music knowledge implicitly (Tillmann, Bharucha, \& Bigand, 2000). Accordingly these listeners may possess knowledge about another musical form without knowing about it, so that it is difficult to assess their musical background in interviews. Music culture mainly spreads with electricity supply (and thus the possibility to operate radios) and religious song (e.g., Christian song in African villages). Unfortunately, opportunities for intercultural comparisons between individuals exposed to completely incongruent music cultures are becoming increasingly rare due to globalization.

MUSIC UNIVERSALS AT DIFFERENT LEVELS OF COMPLEXITY Evidence from intercultural and developmental studies in humans suggests that relatively basic music features such as relative pitch, octave generalization, intervals with simple ratios, and tonality are possibly music universals (for a review, see McDermott \& Hauser, 2005).

In a recent cross-cultural study with autochthonous participants from an African population (Mafa) and Western participants, Fritz et al. (2009) showed the intercultural ability to identify a more complex formal music feature. The Mafas (and the Westerners from the control group) were able to recognize three basic emotions (happy, sad, scary/fearful) expressed in Western music. Both participant groups, the Mafa and the Germans, were naïve to the music of the respective other culture. The Mafa are one of approximately 250 ethnic groups that make up the population of Cameroon. They are located in the Extreme North, in the Mandara mountain range, where the more remote Mafa settlements do not have electrical supply, and are still inhabited by many individuals who pursue a traditional lifestyle, some of whom have never been exposed to Western music.

The study by Fritz et al. was designed to examine the recognition of emotional expressions in Western music using music pieces that had previously been used to investigate the recognition of these emotions in brain damaged patients (Gosselin, Peretz, Johnsen, \& Adolphs, 2006; Gosselin et al., 2005). Stimuli were computer-generated piano music excerpts with durations between 9 and 15 seconds, which were specifically designed to express the emotions happy, sad, and fearful according to Western conventions such that they varied with respect to mode, tempo, pitch range, tone density, and rhythmic regularity. During the experiment, the music stimuli were presented using a CD player and only audible to the participant via headphones to avoid response biases from the experimenter. The participants had to indicate which facial expression from the Ekman archive (happy, sad, fearful, Ekman, 1976) fit best with

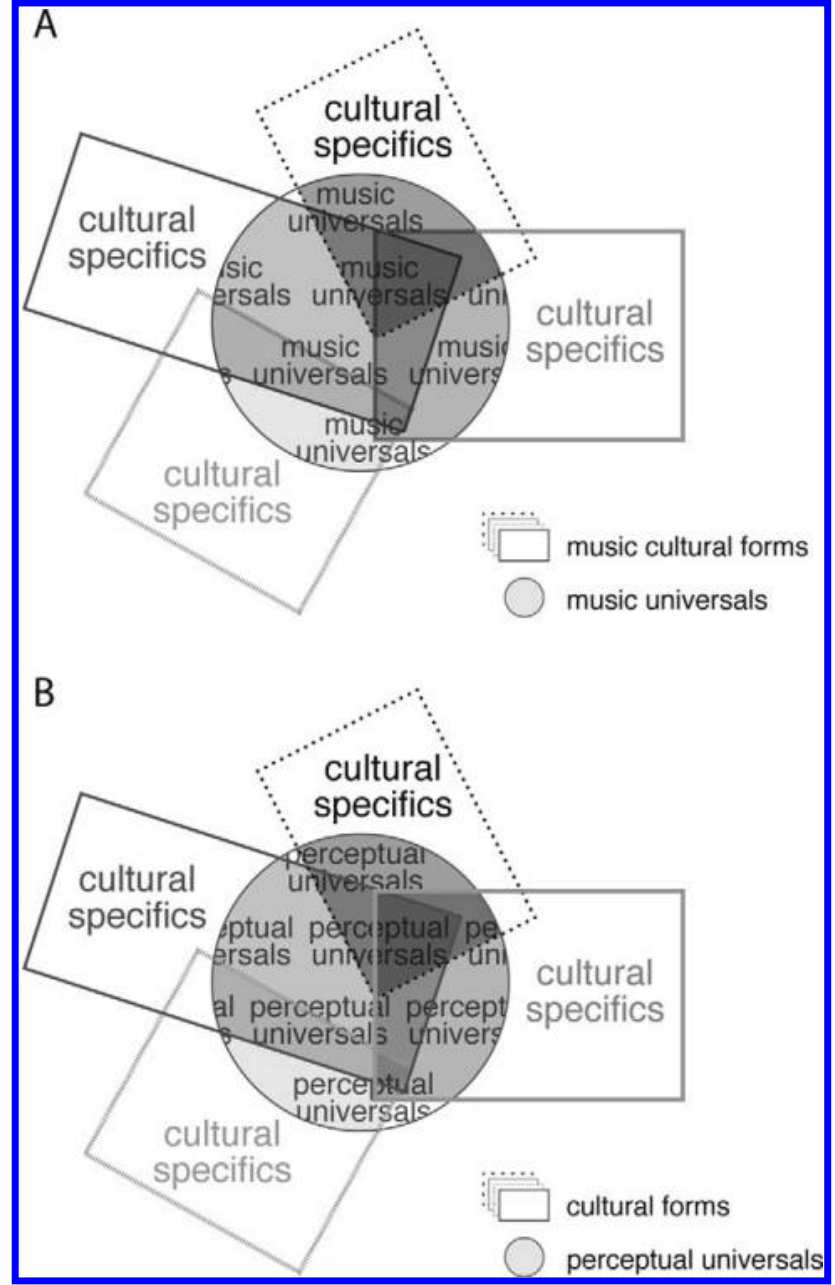

FIGURE 1. A. Dock-in Model of Musical Culture. B. Dock-in Model of Cross-cultural Communication.

the expression of each music excerpt (forced choice). The reported findings indicate that even the supposedly complex musical feature emotional expression can be recognized universally for several emotional expressions in Western music.

This is especially interesting for the model proposed here (Figure 1a) because the musical expression of a variety of emotions like fearfulness and sadness, while recognized in the Western stimuli by the Mafa participants, are-according to interviews with Mafa individuals-never represented in the traditional music of the Mafa people. Thus, they had no experience decoding these two emotional expressions from music, and yet they were capable of recognizing those expressions when embedded in unfamiliar music.

Mafa music practice is based on five short music phrases (of one or two bars) that are performed in 
ceremonies accompanied by vigorous flute playing (for scores of the music material, see supplementary online material of Fritz et al., 2009). These music phrases are also echoed in other contexts such as storytelling with other instrumentations (hand harp, sung voices), where they are said (among the Mafa) to reference the flute playing ceremonies. When the flute performers were asked if the music phrases had an emotional expression or could be played with an emotional expression, this would give rise to bewilderment and objection. The music pieces were not considered to have basic emotional expression. Note however, that the Mafa flute music would still emotionally arouse performers and listeners, but probably by their embedding in sets of cultural practices (e.g., by symbolic association signifying contact with or a presence of your ancestors). It is, however, conceivable that nonbasic, culturally specific emotional expression may be coded in Mafa music (Elfenbein, Mandal, Ambady, Harizuka, \& Kumar, 2002; Markus \& Kitayama, 1991). Importantly for the current argument, it seems that the Mafa have recognized a putatively universal feature of music (that it can convey certain basic emotional expressions), which is not part of their own music repertoire (their music cultural form).

The question arises, why the Mafa music does not include a variety of basic emotional expressions-such as, for example, sadness and scaryness/fearfulness-if the Mafa were capable of recognizing these expressions in the Western music? The answer may be that the recognition of emotional expression from music is not exclusively a musical capability, but instead a capability that evolved as an adaptation to a different challenge, and was then co-opted for music. While emotional expression may be a subcategory of the musical design feature a-referential expressiveness (Fitch, 2005, 2006), this does not entail that the capability for emotional expression processing is an exclusively "musical" capability. Like the capability for the production and perception of many other design features of music, emotional expression processing is probably a spin-off of one or several more general-purpose mechanisms.

The universal capability to identify emotional expressions in Western music is presumably at least partly due to the universal ability to recognize nonverbal patterns of emotional expressiveness (Eckerdal \& Merker, 2009) such as emotional prosody (Juslin \& Laukka, 2003). Interestingly, in ancient Greece the word mousike comprised both the poetry of music and the music of poetry (prose, prosody). Music and speech have many common features and engage largely overlapping brain networks-it seems that the term mousike already covered a continuum from music to speech, so that the ends of such a continuum for them used to be not as ultimate, and irreconcilable (Wachsmann, 1971).

Emotional prosody has been observed to be mimicked by Western music as a means of emotional expression (Juslin, 2001), and other findings indicate that emotional prosody can be recognized universally (Scherer, 1997). This interpretation is consistent with the notion that similar emotion-specific acoustic cues are used to communicate emotion in both speech and music (Juslin \& Laukka, 2003; Scherer, 1995). The use of the adjective musical (instead of the noun music) is thus revealing, because it allows to recognize in a whole collection of sound phenomena some aspects to be considered as musical (Nattiez, 1977).

The expression of emotions is a basic feature of Western music, and the capacity of music to convey emotional expressions is often regarded as a prerequisite for its appreciation in Western cultures. This is not necessarily the case in non-Western music cultures, many of which do not similarly emphasize emotional expressivity. Music cultures may have discovered and developed emotional expression in music at some point, but this was not mandatory for music, and the mediation of emotional expressions probably is not the principal function of music. In Western music, emotional expression is potentially such a prominent feature because Western music is the result of a very long cultural integration process. This probably promoted the cultural transmission of music features that are common denominators between many music cultures and can more likely be understood universally. In other words, in cultures that interact with other cultures, music may gradually become more reliant on universally perceivable cues, such as emotional expressions. In cultures that are more isolated, such as the traditional Mafa culture, it is not necessary that the music is understood by people from different cultural backgrounds because the musical rituals are passed on to the following generation along with a culturally learned semantic imbuement of these musical rituals. Accordingly for the Mafa, universal musical cues such as emotional musical expressions may not be as important.

\section{MODELS CHARACTERIZING THE RELATIONSHIP BETWEEN} UNIVERSAL AND CULTURE-SPECIFIC FEATURES

In the domain of emotional communication, two models have been put forward to conceptualize the relationship between universal and culture-specific features in musical communication. The cue-redundancy model of emotional communication (Balkwill \& Thompson, 1999) emphasized that emotional expressions are likely to be produced with multiple simultaneous cues, so that 
several emotional cues are expressed, only some of which are perceived cross-culturally. This model predicts an in-group advantage for a decoding of emotional communication, because more cues, especially more culturally specific cues, are available to listeners of the same culture. In contrast to the Dock-in Model presented below, this model is (1) specific to emotion in music (but can be extended to speech prosody), and (2) deals only with universally perceivable music features shared between two music cultures (whereas the Dock-in Model also deals with music universals that are not a shared feature of all music cultures or even any music culture). The cue-redundancy model thus applies to emotional musical communication between two cultures, whereas the Dock-in Model provides a way to conceptualize a bigger picture about universals and cultures.

The fractionating emotional systems model (Thompson \& Balkwill, 2010) extends beyond the cue-redundancy model in two ways. First, it accounts for the overlap of cues used in music and speech prosody, arguing that some of those emotional cues are both universally understood and shared by these two channels of communication, whereas other cues are domainspecific (specific to either music or speech prosody) and culture-specific. Second, it acknowledges that throughout development individuals become increasingly sensitive to domain-specific and culture-specific cues. Universal cues provide an emotional connection between between music and speech prosody across all cultures. However, throughout ontogeny, individuals become increasingly attuned to domain-specific and culture-specific cues, leading to a "fractionation" of emotional communication in music and speech prosody, and a fractionation of the emotional cues that are used (in both channels) across cultures. In other words, the fractionating emotional systems model accounts for (1) how ontogeny influences emotional communication (a time course), and (2) the relation between musical and vocal emotional communication. In comparison with the Dock-in Model, the fractionating emotional systems model focuses exclusively on emotional cues, and it does not explicitly address the possibility that musical systems draw upon distinct subsets of universal cues, "docking in" and "docking out" of this shared pool of universal cues at different points in historical time and across cultures.

\section{The Dock-in Model of Music Culture}

The model (Figure 1a) suggests that all music cultures contain both universal and culture-specific features. The more two cultures share a music cultural influence, the more their musical codes (music cultural forms) overlap. This predicts a decoding advantage for individuals whose music cultures more strongly overlap. It suggests that despite a universally shared understanding of a partly common code (music universals) in which all music cultures dock-in, no music culture has implemented the whole set of universal music features in its music repertoire. This predicts that some universal music features may not be found in certain or maybe even any music culture. The current model thus also predicts that a search for specific features that all musics have in common, though an interesting thought experiment (Nettl, 2005), would not suffice to determine music universals, but rather would result in nothing (at best humanly organized sound (Blacking, 1973)) since there is no common denominator in the model. Accordingly, the model depicts how the music repertoires of two cultures can anchor in a set of music universals but do not overlap (the red and green boxes). This would predict that as an extreme, two different music cultures could have integrated different universal music features while sharing none of these between cultures.

The concept of a dock connotes a framework where a vessel might rest temporarily. This corresponds to the temporal dynamics underlying music cultures, acknowledging changes in music systems over historic time. How people make music shifts over time, and these shifts affect the characteristic with which a music culture "docks into" universally perceivable music cues. Accordingly, over historic time cultures may "dock into" and "dock out of" such universal attributes such that more, less, or different cues are utilized, thus shifting the potential for musical cross-cultural perception, interaction, and communication.

A theoretical possibility might even be that a music culture could dock out of all universally perceived music cues, as some Western composers have deliberately pursued (e.g., John Cage's 4'33"), but understanding such cases would entail a discussion about which features should be regarded as musical cues. However, this example indicates that culture (defined as any group of individuals characterized by significantly lower levels of within-group variability than between-group variability in traditions and practices) is merely one level of analysis at which the dock-in model can be applied; in principle it can also be applied to subcultures and even to individual creative acts.

Note that the model also accounts for the theoretical possibility that some music universals have not yet been implemented in any (yet) existing music culture (in 
Figure 1a some music universals are not covered by any music cultural form).

\section{The Dock-in Model of Cross-cultural Perception}

The Dock-in Model can be generalized beyond music culture to encompass all aspects of cross-cultural perception, including cross-cultural communication. Figure $1 \mathrm{~b}$ depicts perceptual cultures docked in to a set of perceptual universals. The Dock-in Model of Music Culture is a specific version of this model because music culture is a specific type of perceptual culture, and music universals are a specific type of perceptual universals. The Dock-in Model of Cross-cultural Perception may be useful to conceptualize also "non-musical" forms of communication such as speech or gesture.

In summary, the Dock-in Model of Music Culture (Figure 1a) provides a theoretical framework to discuss music cultural intersection, and hopefully, to further our understanding of what music universals are, and how they relate to music culture. The findings discussed suggest that music as a means of emotional communicative expression, although probably universally perceived, had to be culturally discovered, and probably transferred from a more general-purpose means of communicative expression. Finally, the Dock-in Model of Music Culture is generalized to include not only music culture, but perceptual cultures. This is depicted in the Dock-in Model of Cross-Cultural Perception (Figure 1b).

\section{Author Note}

This work was supported by the German Academic Exchange foundation (DAAD), D/05/43777. I am grateful to the action editor William Forde Thompson for excellent comments that enhanced the quality of the manuscript.

Correspondence concerning this article should be addressed to Dr. Tom Fritz, Max Planck Institute for Human Cognitive and Brain Sciences, Department of Neurology, Stephanstrasse 1A, 04103, Leipzig, Saxony, Germany. E-mail: fritz@cbs.mpg.de

\section{References}

$\rightarrow$ Balkwill, L. L., \& Thompson, W. F. (1999). A cross-cultural investigation of the perception of emotion in music:

Psychophysical and cultural cues. Music Perception, 17, 43-64.

Blacking, J. (1973). How musical is man? Seattle, WA: University of Washington Press.

Соок, N. (1998). Music: A very short introduction. Oxford, UK: Oxford University Press.

Eckerdal, P., \& Merker, B. (2009). 'Music' and the 'action song' in infant development: An interpretation. In S. Malloch \& C. Trevarthen (Eds.), Communicative musicality. Exploring the basis of human companionship (pp. 241-262). Oxford, UK: Oxford University Press.

Ekman, P. (1976). Pictures of facial affect. Palo Alto, CA: Consulting Psychologists Press.

$\rightarrow$ Elfenbein, H. A., Mandal, M. K., Ambady, N., Harizuka, S., \& Kumar, S. (2002). Cross-cultural patterns in emotion recognition: Highlighting design and analytical techniques. Emotion, 2, 75-84.

$\rightarrow$ Fitch, W. T. (2005). The evolution of music in comparative perspective. Annals of the New York Academy of Sciences, 1060(1), 29-49.

$\rightarrow$ Fitch, W. T. (2006). The biology and evolution of music: A comparative perspective. Cognition, 100, 173-215.

$\rightarrow$ Fritz, T., Jentschke, S., Gosselin, N., Sammler, D., Peretz, I., Turner, R., ET AL. (2009). Universal recognition of three basic emotions in music. Current Biology, 19, 573-576. doi: 10.1016/j.cub.2009.02058 $\rightarrow$ Gosselin, N., Peretz, I., Johnsen, E., \& Adolphs, R. (2006). Amygdala damage impairs emotion recognition from music. Neuropsychologia, 45, 236-244.

$\rightarrow$ Gosselin, N., Peretz, I., Noulhiane, M., Hasboun, D., Beckett, C., Baulac, M., \& Samson, S. (2005). Impaired recognition of scary music following unilateral temporal lobe excision. Brain, 128, 628-640.

Juslin, P. N. (2001). Communicating emotion in music performance: A review and a theoretical framework. In P. N. Juslin \& J. A. Sloboda (Eds.), Music and emotion: Theory and research (pp. 309-337). New York: Oxford University Press.

$\rightarrow$ Juslin, P. N., \& LaukKa, P. (2003). Communication of emotions in vocal expression and music performance: Different channels, same code? Psychological Bulletin, 129, 770-814.

$\rightarrow$ Markus, H. R., \& Kitayama, S. (1991). Culture and the self: Implications for cognition, emotion, and motivation. Psychological Review, 98, 224.

$\rightarrow$ McDermott, J., \& Hauser, M. (2005). The origins of music: Innateness, uniqueness, and evolution. Music Perception, 23, 29-59.

NattieZ, J. J. (1977). Under what conditions can one speak of the universality of music? The World of Music, 191, 92-105.

NettL, B. (2005). The study of ethnomusicology. Thirty-one issues and concepts. Urbana, IL: University of Illinois Press. 
$\rightarrow$ Scherer, K. (1995). Expression of emotion in voice and music. Journal of Voice, 9, 235-248.

$\rightarrow$ Scherer, K. R. (1997). The role of culture in emotion-antecedent appraisal. Journal of Personality and Social Psychology, 73, 902-922.

Thompson, W. F., \& Balkwill, L. L. (2010). Cross-cultural similarities and differences. In P. N. Juslin \& J. A. Sloboda (Eds.), Handbook of music and emotion (pp. 755-788). New York: Oxford University Press.
Tillmann, B., Bharucha, J. J., \& Bigand, E. (2000). Implicit learning of tonality: A self-organized approach. Psychological Review, 107, 885-913.

Turino, T. (2008). Music as social life: The politics of participation. Chicago, IL: University of Chicago Press. Turner, V. (1969). The ritual process: Structure and anti-structure. New York, IL: Aldine.

$\rightarrow$ Wachsmann, K. P. (1971). Universal perspectives in music. Ethnomusicology, 15, 381-384. 